Article

\title{
Bottom-Pressure Development Due to an Abrupt Slope Reduction at Stepped Spillways
}

\author{
Mohammad J. Ostad Mirza Tehrani ${ }^{1,2, * \mathbb{D}}$, Jorge Matos ${ }^{3}$, Michael Pfister ${ }^{4}$ and Anton J. Schleiss ${ }^{1}$ \\ 1 Laboratory of Hydraulic Constructions (LCH), Ecole Polytechnique Fédérale de Lausanne (EPFL), \\ CH-1015 Lausanne, Switzerland; anton.schleiss@epfl.ch \\ 2 Faculty of Civil Engineering, K.N. Toosi University of Technology, Tehran 1996715433, Iran \\ 3 CERIS, Instituto Superior Técnico, Universidade de Lisboa, 1049-001 Lisbon, Portugal; \\ jorge.matos@tecnico.ulisboa.pt \\ 4 Civil Engineering Department, Haute Ecole d'Ingénierie et d'Architecture de Fribourg (HEIA-FR, HES-SO), \\ CH-1705 Fribourg, Switzerland; michael.pfister@hefr.ch \\ * Correspondence: mohammad.tehrani@kntu.ac.ir or mohammadjavad.ostadmirza@alumni.epfl.ch; \\ Tel.: +98-(0)21-8820-1430 (ext. 283)
}

Citation: Ostad Mirza Tehrani, M.J.; Matos, J.; Pfister, M.; Schleiss, A.J. Bottom-Pressure Development Due to an Abrupt Slope Reduction at Stepped Spillways. Water 2022, 14, 41. https://doi.org/10.3390/w14010041

Academic Editor: Marco Franchini

Received: 22 November 2021

Accepted: 17 December 2021

Published: 24 December 2021

Publisher's Note: MDPI stays neutral with regard to jurisdictional claims in published maps and institutional affiliations.

Copyright: (c) 2021 by the authors. Licensee MDPI, Basel, Switzerland. This article is an open access article distributed under the terms and conditions of the Creative Commons Attribution (CC BY) license (https:// creativecommons.org/licenses/by/ $4.0 /)$.

\begin{abstract}
Fluctuating bottom-pressures on stepped chutes are relevant for the spillway design An abrupt slope reduction causes a local alteration of the bottom-pressure development. Little information is available regarding the air-water flow properties near an abrupt slope reduction on stepped chutes, particularly on the local pressure evolution. Nevertheless, the option of providing a chute slope reduction may be of interest in spillway layout. The experiments presented herein include pressure distributions on both vertical and horizontal step faces, subsequent to an abrupt slope reduction on stepped chutes. A relatively large-scale physical model including abrupt slope reductions from $50^{\circ}$ to $18.6^{\circ}$ and from $50^{\circ}$ to $30^{\circ}$ was used, operated with skimming flow. The data indicate a substantial influence of the tested slope reductions on the bottom-pressure development. In the vicinity of the slope reduction, the mean pressure head near the edge of the horizontal step face reached 0.4 to 0.6 times the velocity head upstream of the slope reduction, for critical flow depths normalized by the step height ranging between 2.6 and 4.6 .
\end{abstract}

Keywords: air-water flow; bottom-pressure; skimming flow; slope reduction; stepped spillway

\section{Introduction}

The knowledge of the fluctuating bottom-pressure distribution is important to ensure the structural integrity of smooth and stepped chutes, especially under negative pressures. For stepped chutes with a constant bottom slope, the mean or fluctuating pressures acting on the steps were assessed by several laboratory studies (e.g., [1-13]). On the horizontal face of the step, a typical S-shape pressure distribution was observed, with maximum pressures occurring at the so-called impact flow region, near the outer edge of the step, whereas minimum pressures were noticed on the upstream half of the step face, due to the boundary separation of the recirculating flow (e.g., $[3,4,7,8,11-13])$. For a given critical flow depth normalized by the step height, the impact region was found to increase with decreasing chute slope [13]. In turn, on the vertical face of the step, distinct pressure profiles were obtained in function of the pressure percentile, generally with negative pressures near the upper edge of the vertical face, for the mean and lower pressure percentiles, and positive pressures near the step corner (e.g., [3]). Empirical dimensionless formulae were developed to estimate the mean and extreme pressure profiles on the horizontal and vertical step faces of a steeply sloping stepped chute (e.g., [3]).

As for smooth chutes, the effect of slope reductions on the bottom-pressure development was addressed by few experimental and numerical studies. A study [14], among others, observed a sudden change in pressure and velocity distributions as the flow passed over an abrupt slope reduction at an aerator-deflector. They reported that a slope reduction 
of $\Delta \theta=15^{\circ}$ lead to a pressure increase up to 25 times the hydrostatic pressure near the slope reduction. As for stepped chutes, however, no study was published on the local pressure development near slope reductions, to the knowledge of the authors, except for punctual model studies related to projects of stepped chutes incorporating slope reductions (See Figure 1, e.g., Upper Stillwater Dam in Utah, USA [15], Lower Siah-Bishe Dam in northern Iran [16]). In turn, a significant effect of stepped chute slope reduction was observed on the air entrainment and flow depth developments [17].

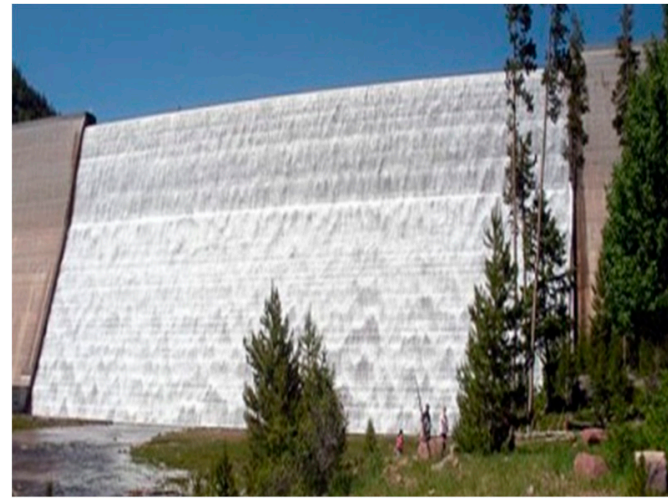

(a)

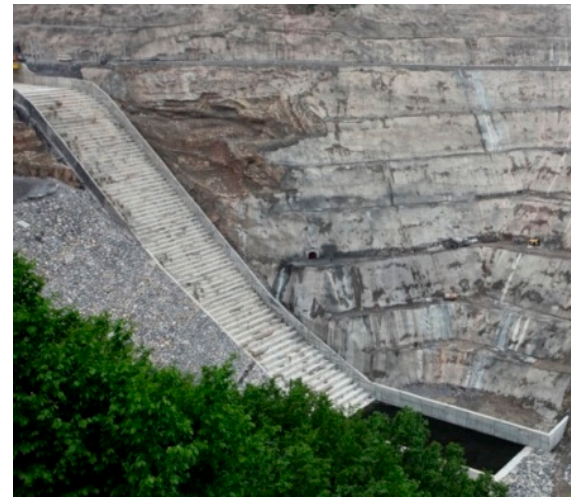

(b)

Figure 1. Stepped spillways with an abrupt slope reduction (a) Upper Stillwater dam, USA (http: / /www.usbr.gov, last accessed date: 15 November 2013); (b) Siah-Bishe lower dam, Iran (http: / / www.iwpco.ir, last accessed date: 21 February 2016).

The present paper follows on from previous work [17] and includes an analysis on the effect of the slope reduction on the bottom-pressure development. Fluctuating pressures were measured systematically along the horizontal and vertical step faces near and far downstream of the slope reduction, in four test runs including $50^{\circ}$ to $18.6^{\circ}\left(\Delta \theta=31.4^{\circ}\right)$ and $50^{\circ}$ to $30^{\circ}\left(\Delta \theta=20^{\circ}\right)$ slope reductions.

\section{Physical Model}

The data presented herein were collected on a large-size stepped chute model, incorporating an abrupt slope reduction [18]. It operated at the Laboratory of Hydraulic Constructions (LCH) at Ecole Polytechnique Fédérale de Lausanne (EPFL), and consisted of three separated modules with different slopes. Each module was $4 \mathrm{~m}$ long and $0.5 \mathrm{~m}$ wide. The upstream module angle from the horizontal (i.e., pseudo-bottom angle) was kept constant with $\theta_{1}=50^{\circ}$ whereas the downstream module angle was set either to $\theta_{2}$ $=30^{\circ}$ or to $18.6^{\circ}$, similar to characteristic RCC or embankment dam angles. Two abrupt slope reductions of $\Delta \theta=20^{\circ}$ and $\Delta \theta=31.4^{\circ}$ were thus tested. The vertical step height was constant with $h=0.06 \mathrm{~m}$, Figure 2 . This step height corresponds to typical prototype values assuming a geometrical scale factor of $1: 10$ or 1:15.

Table 1. Test program.

\begin{tabular}{ccccccccc}
\hline Test & $\left.\boldsymbol{\theta}_{\mathbf{1}} \mathbf{(}^{\circ}\right)$ & $\left.\boldsymbol{\theta}_{\mathbf{2}} \boldsymbol{(}^{\circ}\right)$ & $\boldsymbol{d}_{\boldsymbol{o}}(\mathbf{m})$ & $\boldsymbol{q}\left(\mathbf{m}^{\mathbf{2}} / \mathbf{s}\right)$ & $\boldsymbol{d}_{\boldsymbol{c}} / \boldsymbol{h}(-)$ & $\mathbf{F}_{\boldsymbol{o}}(-)$ & $\mathbf{R}_{\boldsymbol{o}} \mathbf{( - )} \times \mathbf{1 0}^{\mathbf{5}}$ & $\mathbf{W}_{\boldsymbol{o}} \mathbf{0 . 5}^{(-)}$ \\
\hline 1 & 50 & 18.6 & 0.082 & 0.47 & 4.6 & 6.4 & 4.6 & 193 \\
2 & 50 & 30 & 0.082 & 0.47 & 4.6 & 6.4 & 4.6 & 193 \\
3 & 50 & 30 & 0.093 & 0.35 & 3.8 & 3.9 & 3.4 & 135 \\
4 & 50 & 30 & 0.045 & 0.20 & 2.6 & 6.7 & 2.0 & 111 \\
\hline
\end{tabular}




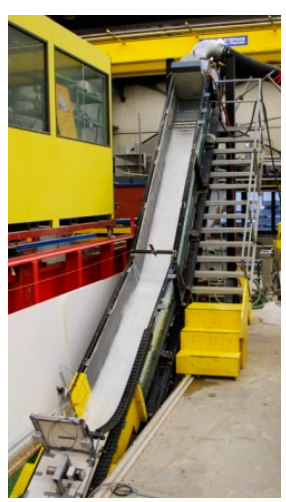

(a)

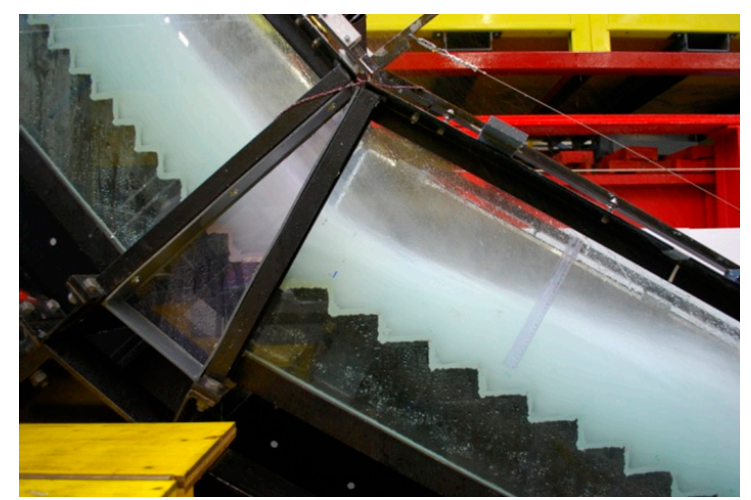

(b)

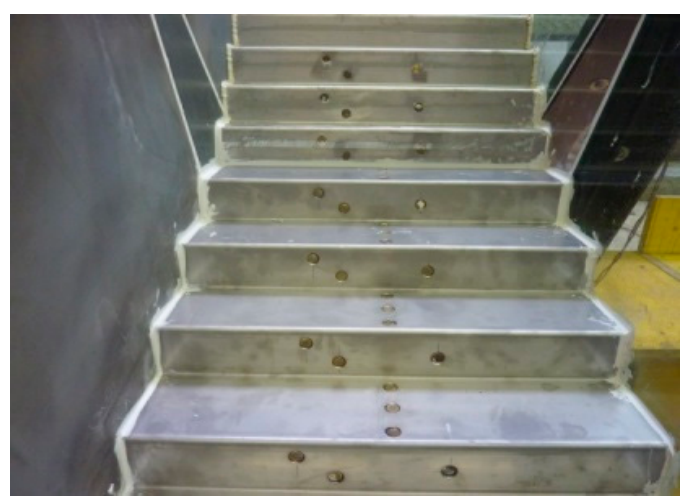

(c)

Figure 2. Physical model of the stepped spillway with an abrupt slope reduction assembled at LCH-EPFL: (a) General view; (b) Side view of configuration associated to test number 2, as per Table 1 $\left(\theta_{1}=50^{\circ} ; \theta_{2}=30^{\circ} ; d_{c} / h=4.6 ; \mathbf{F}_{o}=6.4 ; \mathbf{R}_{\boldsymbol{o}}=4.6 \times 10^{5} ; \mathbf{W}_{o}^{0.5}=193\right.$, flow from left to the right; (c) Pressure transducers with $2 \mathrm{~mm}$ internal (cell) diameter installed in the vicinity of the $50^{\circ}-30^{\circ}$ slope reduction.

A jet-box was provided at the channel upstream end to allow for an independent variation of the inflow depth and Froude number $[5,19]$. Thus, the location of the air entrainment inception was shifted upstream and the developing region of the flow was shortened, in comparison to the typical situation corresponding to an un-gated crest, for identical chute slope, step height and discharge [20]. Hence, gradually varied or quasiuniform air-water flow was reached upstream of the slope reduction, at least for the tested discharge range, as evidenced by [17].

The test program (Table 1) included skimming flow, with unit discharges $0.20 \mathrm{~m}^{2} / \mathrm{s}$ $\leq q \leq 0.47 \mathrm{~m}^{2} / \mathrm{s}\left(2.6 \leq d_{c} / h \leq 4.6\right.$, with $d_{c}=\left(q^{2} / g\right)^{1 / 3}$ as critical flow depth, and $g$ the gravitational acceleration). The Froude $\left(\mathbf{F}_{o}=\left(U_{o} /\left(g d_{0}\right)^{1 / 2}\right)\right.$, Reynolds $\left(\mathbf{R}_{o}=U_{0} d_{o} / v\right)$, and Weber $\left(\mathbf{W}_{o}=\left(\rho U_{0}^{2} d_{0}\right) / \sigma\right)$ numbers at the jet-box are given in Table 1 . Here, $d_{0}$ is the jetbox opening, $U_{o}=q / d_{o}$ is the mean water velocity at the jet-box exit, $v$ is the kinematic viscosity of water, $\rho$ is the water density, and $\sigma$ is the surface tension between air and water. According to previous findings on skimming flow over stepped chutes, (e.g., [7,21-23]), significant scale effects of the macroscopic flow properties are not expected.

The bottom-pressures were measured with piezo-resistive pressure transmitters (Kellerdruck PR-23/8465.2) with cells at the step face with $2 \mathrm{~mm}$ diameter. The measurement range included -0.1 to 0.2 bar. The linearity error including the hysteresis and repeatability was less than $\pm 0.5 \%$ of full scale, with an error of \pm 1.5 mbar for the water temperature range between $0{ }^{\circ} \mathrm{C}$ and $50{ }^{\circ} \mathrm{C}$. The transmitters were installed along the vertical and horizontal step faces near and far downstream of the slope reduction, as shown in Figure 3. Each of the 12 sensors was connected to a 16 bit data acquisition card (NI 6259), optimized for fast sampling rates. For each measurement position, three runs with acquisition time $t_{a c q}=70 \mathrm{~s}$ and $1 \mathrm{kHz}$ frequency were performed. 
(a)

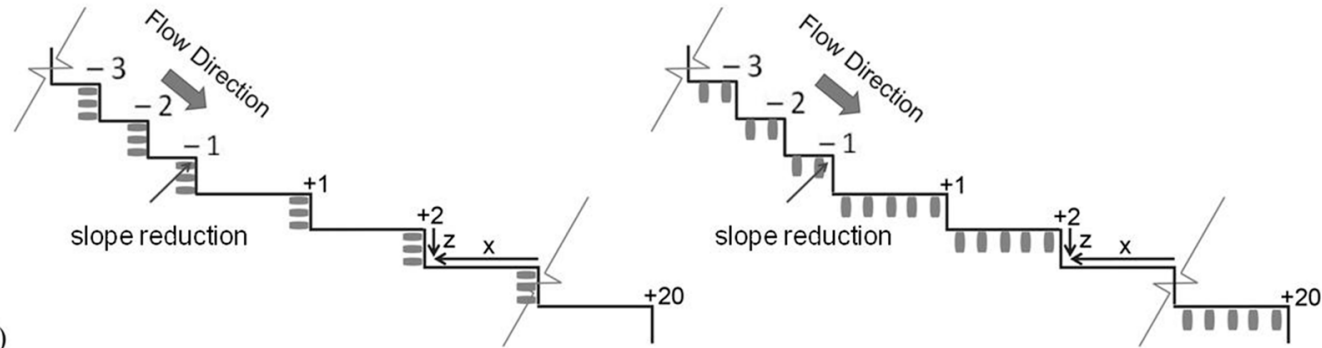

(b)

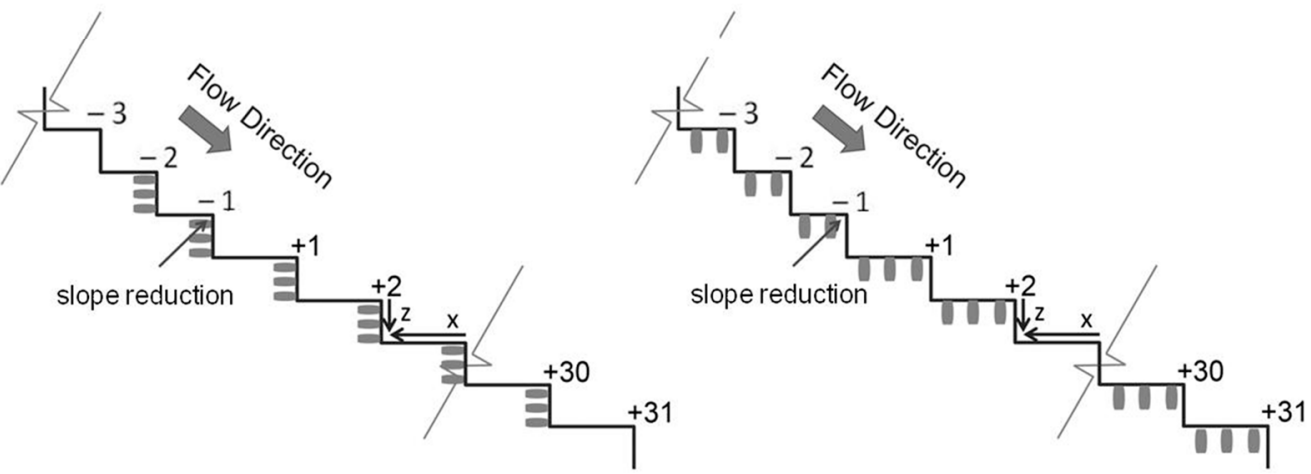

Figure 3. Pressure transmitter positions on the horizontal and vertical step faces, for (a) $50^{\circ}$ to $18.6^{\circ}$ and (b) $50^{\circ}$ to $30^{\circ}$ slope reduction. The step numbers downstream of the slope reduction are positive; otherwise, they are negative.

\section{Results and Discussion}

To investigate the slope reduction effect on the bottom-pressure development and to compare it with former results on constantly sloping stepped chutes, the present data are illustrated along the horizontal and vertical faces:

1. "near" the slope reduction (i.e., in the reach where the main flow properties are influenced by the slope reduction);

2. "far" upstream of the slope reduction (i.e., ahead of the reach where the main flow properties are influenced by the slope reduction);

3. "far" downstream of the slope reduction (i.e., beyond the reach where the main flow properties are influenced by the slope reduction).

According to [17], the limit steps uninfluenced by the slope reduction are numbered -3 ("far" upstream, $\theta_{1}=50^{\circ}$ ), +31 ("far" downstream, $\theta_{2}=30^{\circ}$ ), and +20 ("far" downstream, $\left.\theta_{2}=18.6^{\circ}\right)$.

\subsection{Horizontal Step Face}

\subsubsection{Bottom-Pressure Profiles}

Figure 4 shows the mean, and the 5th and 95th percentiles of the dimensionless pressures $p /(\gamma h)$ along the horizontal step faces, where $p$ is the measured bottom-pressure, $\gamma$ is the specific water weight, and $h$ the step height. More precisely, Figure 4 illustrates the data for the $50^{\circ}$ to $18.6^{\circ}$ slope reduction, and for $d_{c} / h=4.6$ at different steps.

The results on the steps where the main flow properties are uninfluenced by the slope reduction (steps -3 and +20 of Figure $4 a$,c, respectively) show that the pressure tends to increase along the horizontal face with decreasing $x / l$, regardless of the pressure percentile, except in the vicinity of both the step edge and the step corner. This trend is not clearly observed for the $50^{\circ}$ chute because of the limited number of transmitter positions (Table $2, x / l=0.35 ; x / l=0.64$ ). The $S$-shape pressure distribution for stepped chutes without a slope reduction (e.g., $[12,13])$ is evident herein at step $+20\left(18.6^{\circ}\right.$ module) located "far" downstream of the slope reduction (Figure 4c). Globally, on each step, the smallest pressures were observed along the upstream portion $(x / l>0.5)$ of the horizontal 
faces, and the maximum pressures occurred close to the edges $(x / l<0.5)$. For $d_{c} / h=4.6$, the highest pressures were obtained at $x / l=0.3$, closely followed by those at $x / l=0.1$. Similar results were obtained for the $30^{\circ}$ module at steps +30 and +31 , as shown in [18]. Therein, the $S$-shape far downstream of the slope reduction was less pronounced, likely due to a lower density of measurement points.

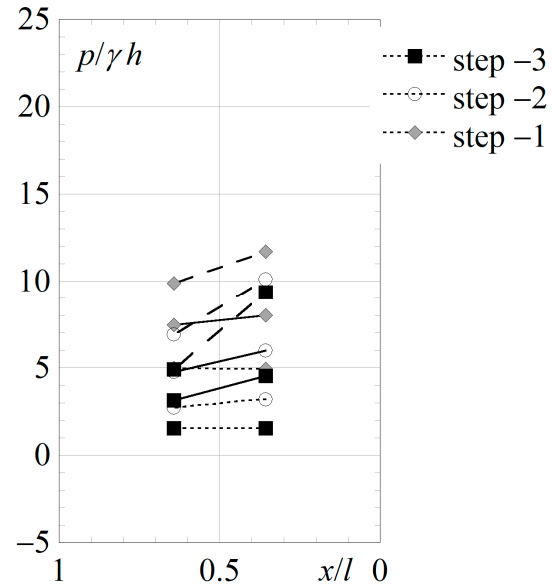

(a)

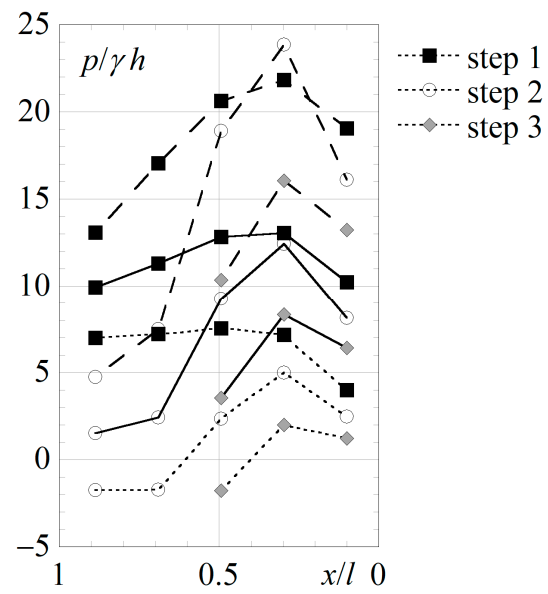

(b)

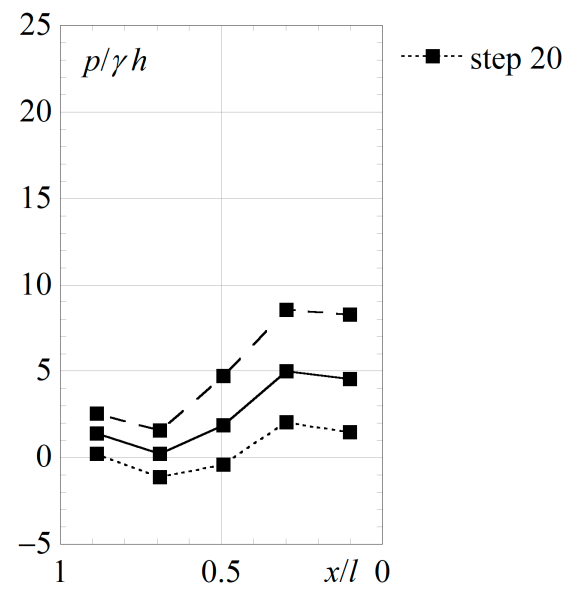

(c)

Figure 4. Dimensionless pressures $p /(\gamma h)$ on the horizontal step faces for the $50^{\circ}$ to $18.6^{\circ}$ slope reduction and $d_{c} / h=4.6$ : (a) upstream of the slope reduction, (b) just downstream, and (c) "far" downstream; $(\cdots)$ th percentile, $(-)$ mean, and (-) 95th percentile.

Table 2. Pressure transmitter positions on horizontal step faces (see Figure 3).

\begin{tabular}{ccccccc}
\hline $\boldsymbol{\theta}\left({ }^{\circ}\right)$ & $\boldsymbol{l}(\mathbf{m})$ & & $x / l$ & - & - \\
\hline 50 & 0.050 & 0.35 & 0.64 & - & - & - \\
30 & 0.104 & 0.17 & 0.50 & 0.84 & 0.70 & 0.88 \\
18.6 & 0.178 & 0.10 & 0.30 & 0.50 & 0.70 \\
\hline
\end{tabular}

The above findings are consistent with those of others (e.g., $[2-9,11-13,22,24])$. They demonstrate that (1) the pressure near the step edge is influenced by flow impact, i.e., the interaction of the lower edge of the shear layer formed downstream of each step singularity with the horizontal face of the step, as characterized in [25], (2) the step corner pressure is influenced by the flow recirculation, and (3) the highest absolute pressures occur at the impact region, near the flow separation in between these two regions. Further, for a given critical flow depth normalized by the step height (relative critical flow depth), the impact region was found to increase with decreasing chute slope [12]. However, the differences were relatively small for chute angles from the horizontal between $19^{\circ}$ and $30^{\circ}$. In turn, for a given chute slope, the impact region was noted to decrease with increasing relative critical flow depth. Only a slight change of the maximum pressure location occurred with varying discharge, on $18.4^{\circ}$ and $26.6^{\circ}$ chutes [13].

The slope reduction generates a flow deviation, with pronounced local bottompressures. The bottom-pressure starts to increase when approaching the slope reduction (steps -2 and -1 , Figure $4 a$ ). Immediately downstream of the slope reduction, larger values of the mean as well as of the 5 th and 95th percentiles were recorded (steps +1 and +2 , Figure 4b). A similar trend was observed on an abrupt slope reduction on stepped [15] and on smooth chutes [14]. From the model studies of the Upper Stillwater dam stepped spillway, with a slope reduction from $72^{\circ}$ to $59^{\circ}\left(\Delta \theta=13^{\circ}\right)$, mean pressures obtained with piezometers located near the step edge were shown to increase shortly upstream of the slope reduction, with highest values recorded at this location, regardless of the tested 
reservoir heads [15]. Similarly, [14] observed that pressures were influenced by the slope reduction slightly upstream of the latter, despite supercritical flow. Therein, three slope reductions were tested, $\Delta \theta=6.22^{\circ}, 10^{\circ}$ and $15^{\circ}$. This phenomenon can be explained by the non-hydrostatic pressure distribution in the vicinity of the slope reduction, influencing the flow properties already upstream of the latter, even under supercritical flows.

The above observations for $d_{c} / h=4.6$ can be extended to $2.6 \leq d_{c} / h \leq 4.6$, as shown for the $50^{\circ}$ to $30^{\circ}$ slope reduction in Figure 5, for the 95th pressure percentile. The pressures are noted to increase with discharge. In $[3,5]$ maximum pressures of the same order of magnitude of those presented herein were observed for the steps located "far" upstream or downstream of the slope reduction (steps -3 for $50^{\circ},+31$ for $30^{\circ}$ ), for similar slope, relative critical flow depth, and relative position on the step face. Overall maximum values of $p /(\gamma h) \approx 5$ and 5.5 were obtained in those studies, with $51.2^{\circ}$ and $30^{\circ}$ stepped chutes, for $d_{c} / h=2.3$ and 2.7, respectively. It should be noted that, in the present study, only two pressure transmitter positions were available for the $50^{\circ}$ chute, and higher pressures would be expected near the step edge, as shown in [3]. In the latter study, 95th pressure percentiles of $p /(\gamma h) \approx 6.5$ were obtained in the vicinity of the step edge $(x / l \approx 0.06)$, for $d_{c} / h=2.3$. The relatively higher values obtained in the present study for the $50^{\circ}$ chute (e.g., $p /(\gamma h) \approx$ 7.5 at step -3 , for $x / l=0.35$ and $d_{c} / h=2.6$ ) in relation to those of [3] may be due to the smaller contact area of the pressure transmitter $(2 \mathrm{~mm}$ versus $8 \mathrm{~mm})$, and to the slightly larger relative critical flow depth $\left(d_{c} / h=2.6\right.$ versus $\left.d_{c} / h=2.3\right)$.

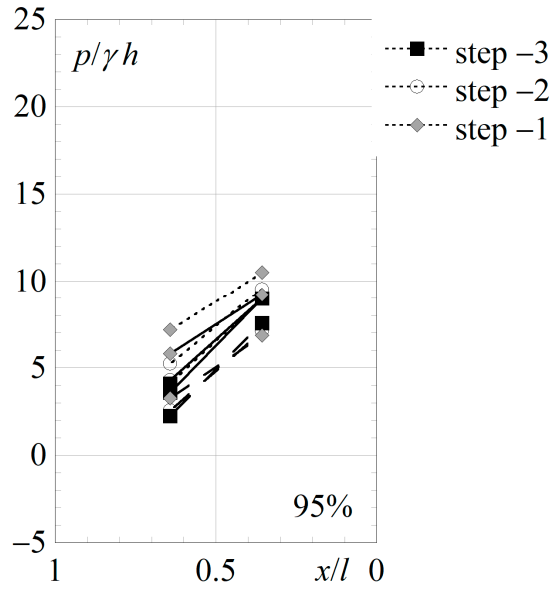

(a)

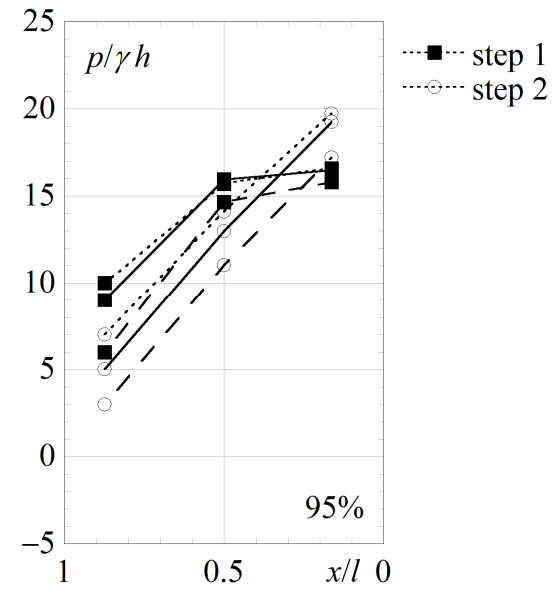

(b)

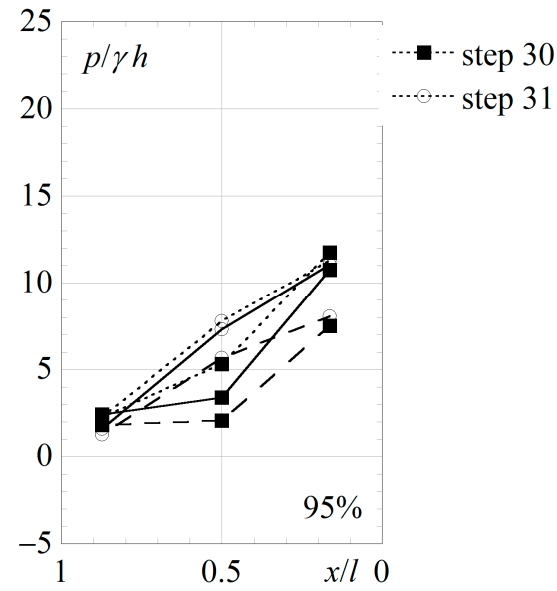

(c)

Figure 5. Dimensionless 95th percentile pressures $p /(\gamma h)$ on the horizontal step faces for the $50^{\circ}$ to $30^{\circ}$ slope reduction: (a) upstream of the slope reduction, (b) just downstream, and (c) "far" downstream; $d_{c} / / h=(-) 2.6,(-) 3.8$, and $(\cdots) 4.6$.

\subsubsection{Development of the Local Maximum Pressure}

The development of the measured mean and the 5th and 95th percentiles of the local maximum pressure (at $x / l=0.35,0.17$ and 0.3 , respectively on the $50^{\circ}, 30^{\circ}$, and $18.6^{\circ}$ sloping chutes) along the chute are shown in Figure 6 for the $50^{\circ}$ to $18.6^{\circ}$ and the $50^{\circ}$ to $30^{\circ}$ slope reduction configurations, respectively, with $d_{c} / h=4.6$. The effect of the slope reduction on the pressure starts upstream of the slope reduction, as indicated above. A significant pressure increase appears between steps -2 and +1 or +2 . Further downstream, the pressure decreases towards the uninfluenced values (at step +20 and +31 , for the $18.6^{\circ}$ and $30^{\circ}$ modules, respectively). For the $50^{\circ}$ to $18.6^{\circ}$ slope reduction and 95 th percentile, the pressure head in the vicinity of the slope reduction (step +2) is almost three times that upstream of the slope reduction (step -3), or far downstream (step +20), whereas for the $50^{\circ}$ to $30^{\circ}$ slope reduction, such ratio is approximately equal to two. Hence, a "pronounced" slope reduction from $50^{\circ}$ to $18.6^{\circ}$ resulted in higher ratios compared to those 
of the "mild" $50^{\circ}$ to $30^{\circ}$ slope reduction. A similar trend was observed for the 5 th percentile and particularly for the mean, as well as for distinct relative critical flow depths $\left(d_{c} / h=2.6\right.$ and 3.8), on the $50^{\circ}$ to $30^{\circ}$ slope reduction (not shown herein).

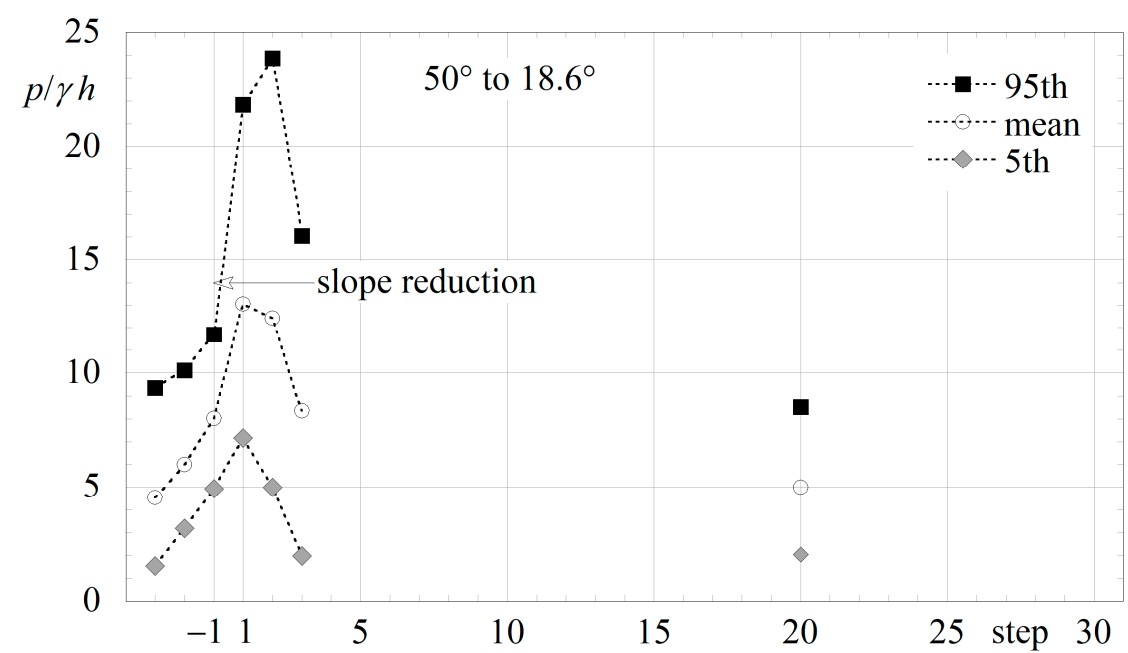

(a)

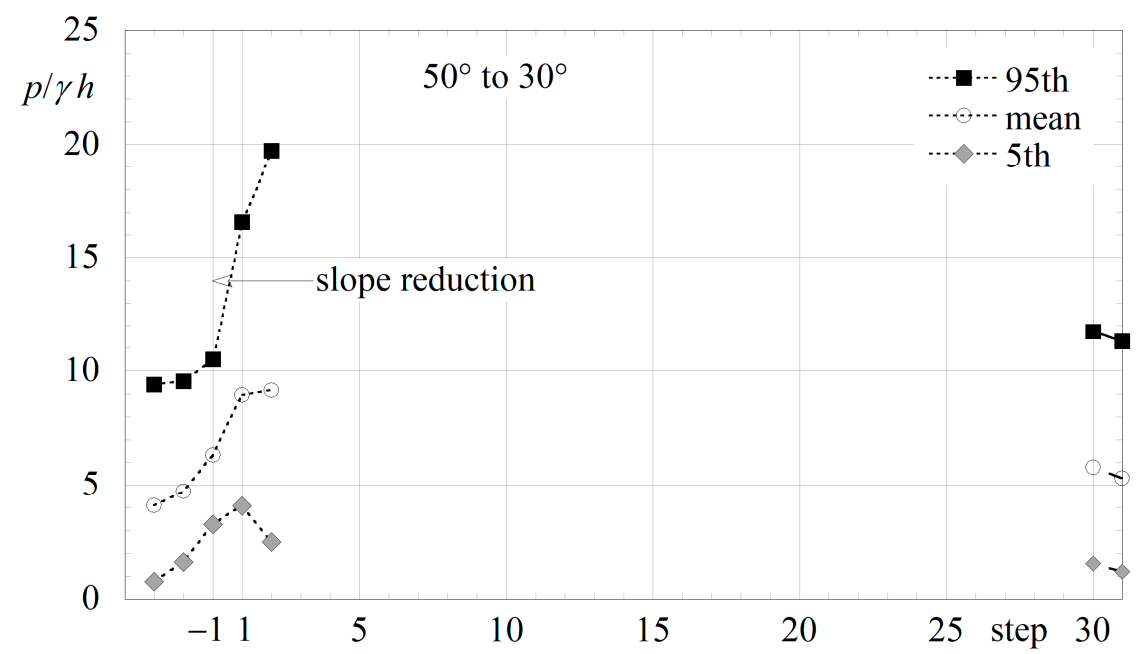

(b)

Figure 6. Development of the dimensionless pressure $p /(\gamma h)$ for $d_{c} / h=4.6$, for (a) the $50^{\circ}$ to $18.6^{\circ}$ slope reduction, at $x / l=0.35$ on the $50^{\circ}$ sloping chute and $x / l=0.3$ on the $18.6^{\circ}$ sloping chute, and (b) the $50^{\circ}$ to $30^{\circ}$ slope reduction, at $x / l=0.35$ on the $50^{\circ}$ sloping chute and $x / l=0.17$ on the $30^{\circ}$ sloping chute.

3.1.3. Equivalent Clear-Water Depth and Mean Pressure Development near the Slope Reduction

Based on air concentration measurements $([17,18])$, the normalized equivalent clearwater depth $d / h$ near the slope reduction is shown in Figure 7a as a function of $X=\left(x^{\prime}-\right.$ $\left.x_{s c}\right) / h$, with $x^{\prime}$ as the streamwise coordinate starting at the jet-box, and $x_{s c}$ as the distance between the jet-box and the slope reduction (subscript sc). The equivalent clear-water depth $d$ is given as $d=\left(1-C_{m}\right) Y_{90}$, where $Y_{90}$ is the characteristic mixture flow depth defined as the distance between the pseudo-bottom and the point where the local air concentration $C=0.90$, and $C_{m}$ is the mean (depth-averaged) air concentration ([17]). The values of $d / h$ increase near the slope reduction $(X=0)$ due to the flow curvature initiated slightly upstream. Immediately downstream of the slope reduction, $d / h$ decreases $(X>0)$. Far 
downstream, $d / h$ reaches the uninfluenced values of those chute slopes ([17]). A trend of flow depth increase upstream of the slope reduction, and subsequent decrease immediately downstream, was also reported by [15].

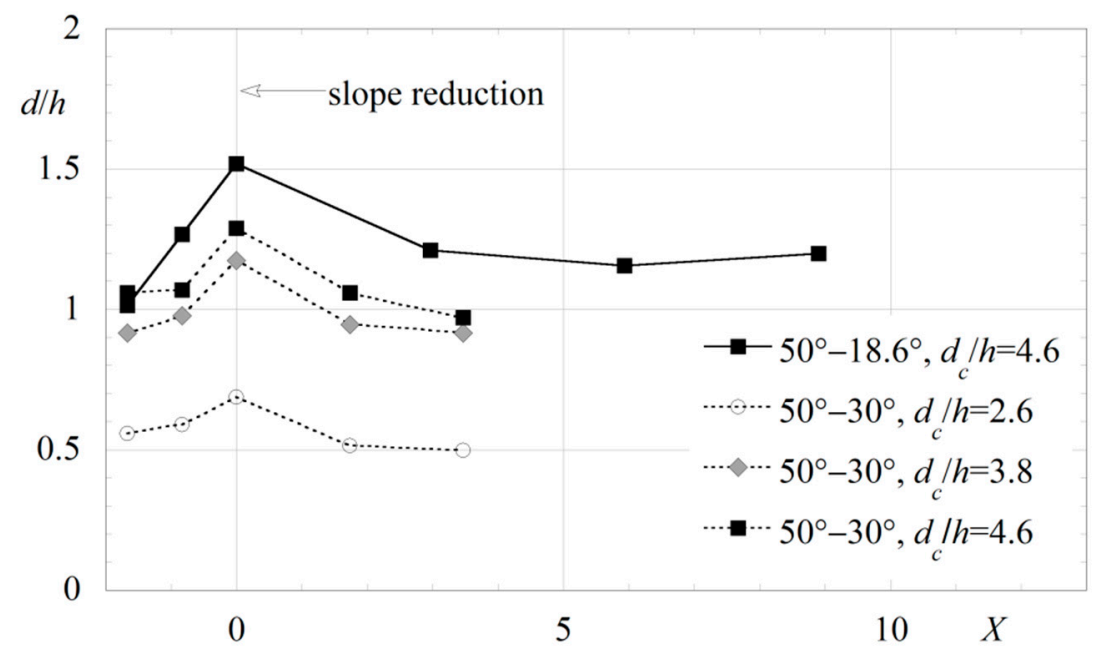

(a)

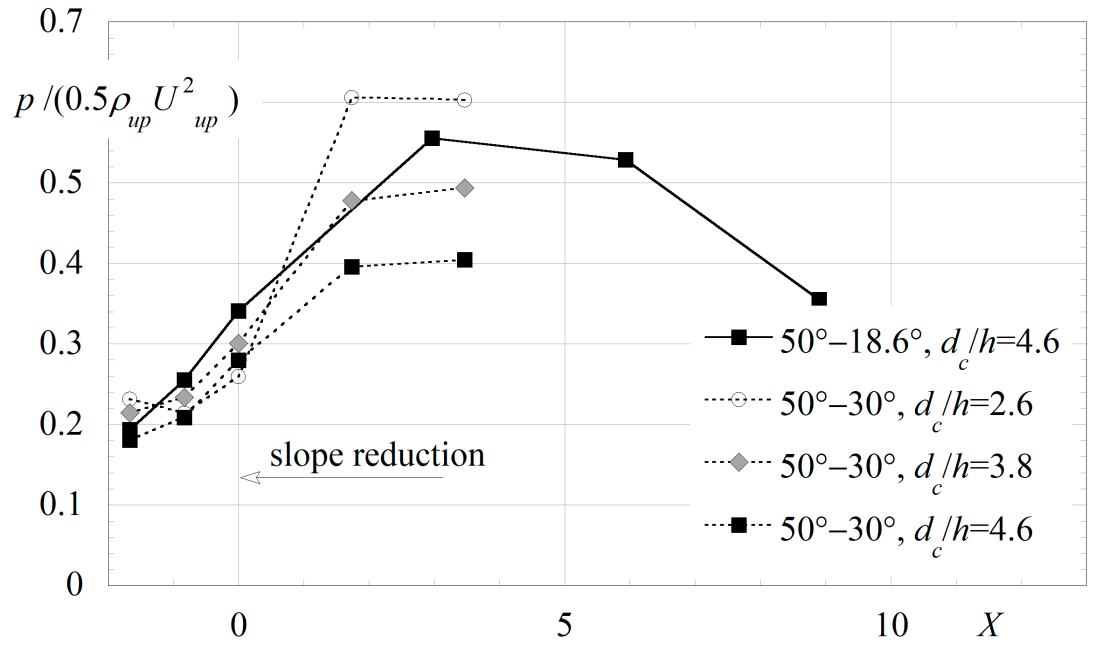

(b)

Figure 7. Streamwise development of the (a) normalized equivalent clear-water depth $d / h$ and (b) normalized mean pressure $p /\left(0.5 \rho_{u p} U^{2}\right.$ up $)$ on the horizontal step faces, at $x / l=0.35,0.17$, and 0.3 , respectively, on the $50^{\circ}, 30^{\circ}$, and $18.6^{\circ}$ sloping chutes.

To highlight the development of the mean pressure on the horizontal step faces near the slope reduction (at $x / l=0.35,0.17$, and 0.3 , respectively, on the $50^{\circ}, 30^{\circ}$, and $18.6^{\circ}$ sloping chutes) the normalized pressure $p /\left(0.5 \rho_{u p} U^{2}{ }_{u p}\right)$ is introduced, with $\rho_{u p}=\rho(1-$ $C_{\text {mup }}$ ) as the density of the air-water flow upstream (subscript up) of the slope reduction yet uninfluenced by the latter (at step -3 being $X=-1.8), C_{m u p}$ as mean air concentration, $d_{u p}$ as equivalent clear-water depth, and $U_{u p}=q / d_{u p}$ as mean water velocity, all at step -3 . Results of $C_{m u p}, d_{u p}$, and $U_{u p}$ can be found in [18].

The results are shown in Figure $7 \mathrm{~b}$. The mean bottom-pressures were those at $x / l$ $=0.35,0.17$, and 0.3 , respectively, on the $50^{\circ}, 30^{\circ}$, and $18.6^{\circ}$ modules. The normalized pressure noticeably increases when approaching the slope reduction. Shortly downstream of the latter (up to steps +1 or $+2,1.7<X<3.5$ ), the mean bottom-pressure head continues to increase, due to the impact of the flow on the longer horizontal step face, attaining 
0.4 to 0.6 times the velocity head upstream of the slope reduction, for the tested range of relative critical flow depths. These values of the normalized pressure are of the same order of magnitude of those obtained for concave vertical curves on smooth chutes, with curvature radii normalized by the flow depth upstream of the curved reach (normalized curvature radii) ranging approximately between 3.3 and 5 , according to the application of the simplified centrifugal pressure or the free-vortex methods [26].

For the present study, it was not possible to obtain accurate estimates of the flow curvature radii through visual observation, due to the complexity of the highly turbulent airwater flow in the vicinity of the slope reduction, along with visual observation constrains of the experimental set-up. In alternative, the characteristic mixture flow depth $Y_{90}$ was used to obtain a rough estimate of the normalized flow curvature radii near the abrupt slope reduction. The normalized curvature radii for the $50^{\circ}$ to $30^{\circ}$ slope reduction were practically independent of the relative critical flow depth $\left(3.5 \leq R / Y_{90} \leq 3.7\right)$, whereas a larger value was obtained for the $50^{\circ}$ to $18.6^{\circ}$ slope reduction, with $d_{c} / h=4.6\left(R / Y_{90}=5.1\right)$. These values are practically within the range of those estimated herein for concave vertical curves on smooth chutes ( 3.3 to 5). Overall, these normalized curvature radii are lower than that recommended for design of conventional chute transitions, according to [27].

By using the ratio $p /\left(\gamma d_{u p} \cos \theta\right)$, values increasing from 6 (step -2$)$ to 21 (step +1 or +2$)$ were observed in the vicinity of the slope reduction, for $2.6 \leq d_{c} / h \leq 4.6(0.16 \mathrm{~m}$ $\leq d_{c} \leq 0.28 \mathrm{~m}$ ) (not shown herein). A similar trend was reported by [14] on an abrupt slope reduction at an aerator-deflector, namely for $\Delta \theta=15^{\circ}$. For such slope reduction, they reported pressure heads ranging between 3 and 23 times the upstream uninfluenced hydrostatic pressure, at a distance to the slope reduction of less than twice the upstream flow depth, for $0.14 \mathrm{~m} \leq d_{c} \leq 0.22 \mathrm{~m}$.

Lower discharges show strong fins with flow bulking over a considerable distance due to the slope reduction, possibly because of high relative bottom-pressures [17]. This condition is evident immediately downstream of the slope reduction, where a larger normalized pressure was observed for low discharges (Figure $7 \mathrm{~b}$, compare $d_{c} / h=2.6,3.8$ and 4.6 on the $50^{\circ}$ to $30^{\circ}$ slope reduction configuration, $\left.0<X<3.5\right)$. With an increasing relative slope reduction from $\Delta \theta=20^{\circ}$ to $\Delta \theta=31.4^{\circ}$, the maximum normalized pressure also increased by approximately $40 \%$ (Figure $7 \mathrm{~b}$, compare $d_{c} / h=4.6$ on the $50^{\circ}$ to $18.6^{\circ}$ and $50^{\circ}$ to $30^{\circ}$ slope reduction configurations, where $X \approx 3.5$ ).

\subsubsection{Probability Distribution of Fluctuating Pressures}

The probability distribution function $F$ of fluctuating pressures yet uninfluenced by the slope reduction are compared with the Normal (Gaussian) distribution (straight dashed line) for $d_{c} / h=4.6$ in Figure 8 . The results indicate that the probability plots near the step corners $(x / l>0.5)$ are different from those near the step edges $(x / l<0.5)$, irrespective of the chute slope.

Near the step edges $(x / l<0.5)$, higher and positive skewness was found, showing that pronounced negative pressures are not as frequent as large positive ones [28]. Hence, a Normal distribution will underestimate the maximum pressures near the step edges, as shown in [11]. Close to the step edge, negative pressures with very low probabilities were recorded.

Smaller pressure fluctuations were observed near the corners $(x / l>0.5)$. Slightly negative or null values of skewness were observed (e.g., at $x / l=0.88$ and 0.70 ). However, in general, positive pressure values were more frequent than negative pressure values.

Pronounced pressure minima occur near the step corner $(x / l=0.64,0.84$, and 0.88 respectively on $50^{\circ}, 30^{\circ}$ and $18.6^{\circ}$ module). Along the inner region of the steps towards the corner $(x / l>0.50)$, the pressure distribution is in better agreement with the Normal distribution, than the downstream portion of steps. A kurtosis greater than 3 was observed for all cases. These observations are consistent with those found by [11]. 


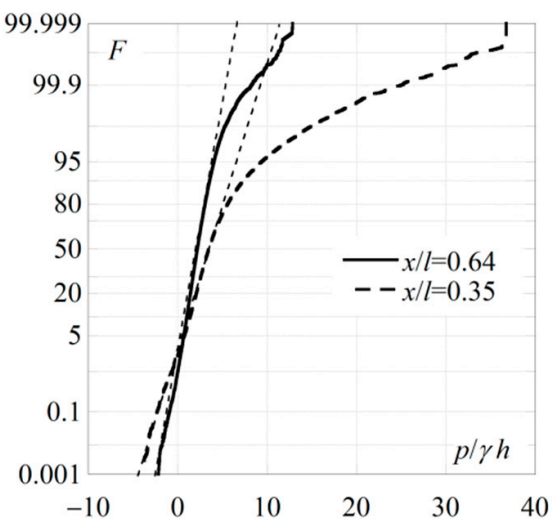

(a)

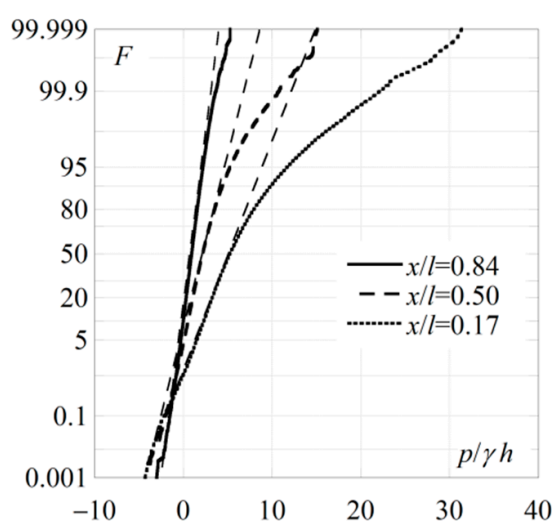

(b)

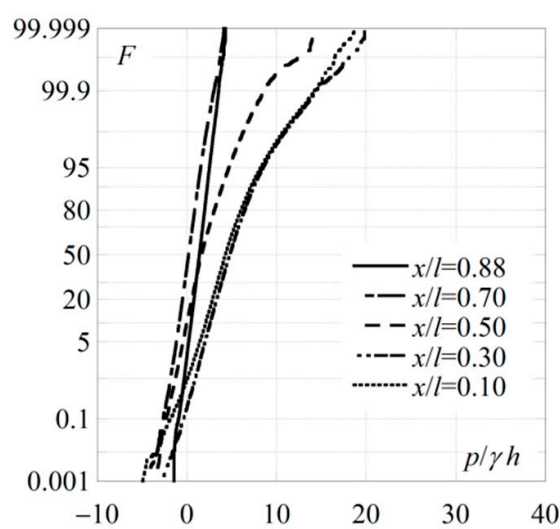

(c)

Figure 8. Probability distribution function $F$ of fluctuating pressures yet uninfluenced by the slope reduction, for $d_{c} / h=4.6$ and (a) $50^{\circ}$ module (step -3), (b) $30^{\circ}$ module (step 31 , and (c) $18.6^{\circ}$ module (step 20). (-) Normal distribution.

\subsection{Vertical Step Face}

\subsubsection{Bottom-Pressure Profiles}

Figure 9 shows the mean and the 5th and 95th percentiles of the dimensionless pressures $p /(\gamma h)$ along the vertical step faces (at $z / h=0.3,0.55$ and 0.70$)$, near and far downstream of the $50^{\circ}$ to $18.6^{\circ}$ slope reduction, for $d_{c} / h=4.6$. The results show that the vertical position has a small influence on the pressure, for $0.3 \leq z / h \leq 0.7$. Similar results were found by others, within this range of positions along the vertical step face (e.g., $[2-4,6-8,11,13,22,24])$. However, smaller values would be expected to occur near the step edge due to the flow separation $[2-4,6-8,11,13,22,24,29,30]$. Such positions were not adopted in the present study due to the size of the transmitters. Similar findings were obtained for the $50^{\circ}$ to $30^{\circ}$ slope reduction, as shown in [18].

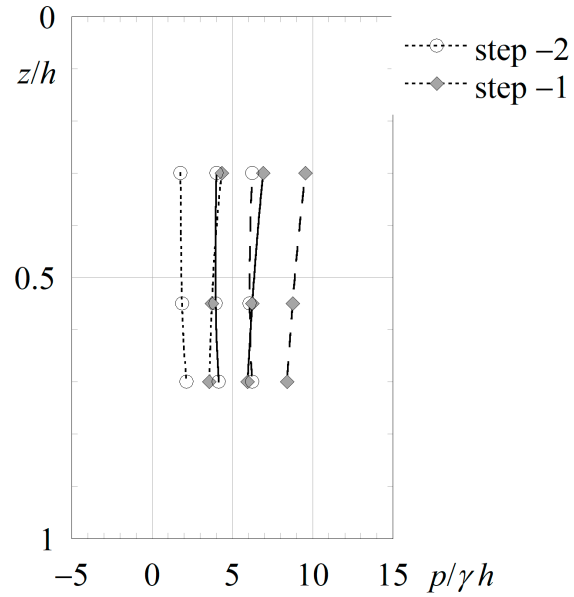

(a)

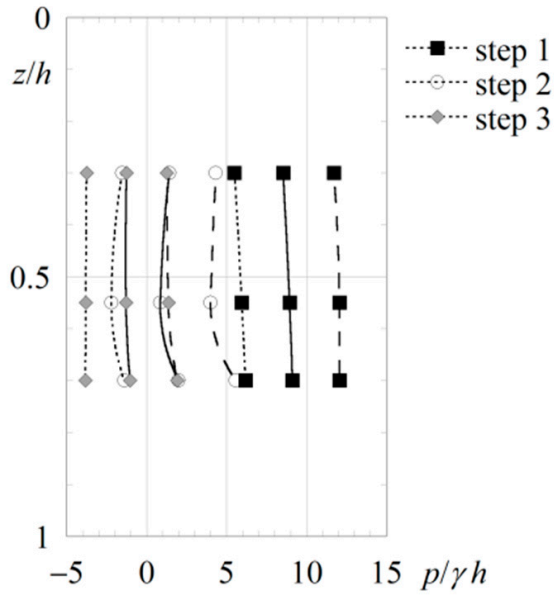

(b)

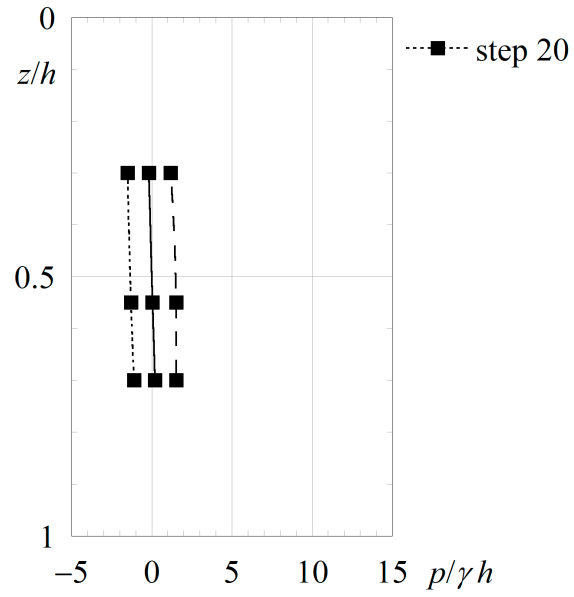

(c)

Figure 9. Dimensionless pressures $p /(\gamma h)$ on the vertical step faces for the $50^{\circ}$ to $18.6^{\circ}$ slope reduction and $d_{c} / h=4.6$ : (a) upstream of the slope reduction, (b) just downstream, and (c) "far" downstream; $(\cdots) 5$ th percentile, $(-)$ mean, and (-) 95 th percentile.

When approaching the slope reduction, a local pressure increase at the mean and considered percentiles appeared, as observed for the horizontal step faces (Figure 5), yet less pronounced. Immediately downstream of the slope reduction (up to step +3 ), the 
pressure decreased significantly, and the minima of the 5th percentile occurred as $p /(\gamma h)$ $=-4$, which would not lead to cavitation on a typical prototype of $0.9 \mathrm{~m}$ high steps. In addition, air concentrations larger than 0.1 were measured near the pseudo-bottom, due to significant self-aeration upstream of the slope reduction [17]. Hence, even higher extreme negative pressures that would likely occur near the step edge, namely for a more conservative 0.1 th pressure percentile (e.g., $[7,11]$ ), should not be critical in terms of cavitation damage, for similar geometry and flow conditions. However, this conclusion should not be generalized for high velocity, clear-water flows subject to slope reductions, which may occur for high unit discharges and slope reductions located upstream of the point of inception of air entrainment. In such a scenario, and in the absence of an adequate air concentration close to the pseudo-bottom, cavitation damage might occur, as one may infer from $[31,32]$.

\subsubsection{Probability Distribution of Fluctuating Pressures}

The probability distribution function $F$ of dynamic pressures yet uninfluenced by the slope reduction are compared with the Normal distribution (straight dashed line) in Figure 10 , focusing only on step -2 , the $50^{\circ}$ module, and $d_{c} / h=4.6$. The data trend of Figure 10 differs from that observed for the horizontal step faces (Figure 8). Near the step edge $(z / h=0.3)$, the skewness decreases and negative values appear, indicating that negative pressures are more frequent than positive pressures [28]. There, a Normal distribution underestimates pressure minima (as stated also by [11]), so that the pressure transmitters indicate lower negative pressures.

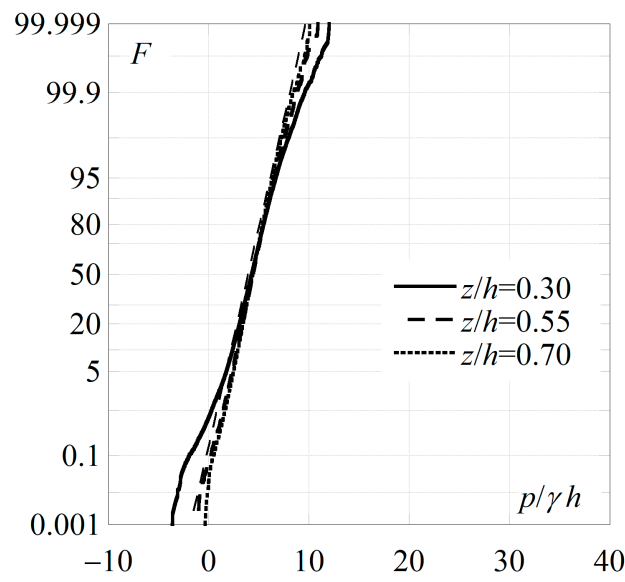

Figure 10. Probability distribution function $F$ of fluctuating pressures yet uninfluenced by the slope reduction, for $d_{c /} h=4.6$ and the $50^{\circ}$ module (at step -2 ), at $z / h=0.30, z / h=0.55$, and $z / h=0.70$. (-) Normal distribution.

\section{Conclusions}

Stepped chutes incorporating an abrupt slope reduction have already been built and operated. However, they have not yet been the focus of detailed research. Herein, a physical model study on abrupt slope reductions at stepped chutes is presented, providing pressures on the vertical and horizontal step faces in skimming flow. An upper module with a $50^{\circ}$ bottom angle was connected to a lower module, with either a $30^{\circ}$ or $18.6^{\circ}$ angle.

From this study, the following conclusions can be drawn:

- A global increase of the bottom-pressure (for the mean, and the 5th and 95th percentiles) occurs on the horizontal step faces, near the slope reduction. A similar but less pronounced increasing trend occurs on the vertical step faces.

- In the vicinity of the slope reduction, the mean pressure head near the edge of the horizontal step face attains 0.4 to 0.6 times the velocity head upstream of the slope reduction, for relative critical flow depths ranging between 2.6 and 4.6. For this range of normalized pressure heads, the estimated radii of curvature of the flow is of the 
same order of magnitude of those reported on concave vertical curves on smooth chutes.

- Downstream of the slope reduction, the pressures on the horizontal step faces near the edge decrease rapidly and approach typical values for uninfluenced steps.

- $\quad$ Negative pressure values (5th percentile) were measured on the vertical step faces near the slope reduction. Although they were hardly severe enough to lead to cavitation on a typical prototype, the transducer positions were not close enough to the step edge. In addition, a much lower percentile (i.e., 0.1 th percentile) should be adopted if cavitation tendency is to be predicted.

A substantial effect on the bottom-pressure development was observed near the slope reduction, which should be considered to estimate the total thrust and bending moment on the chute walls. However, the pressure variations caused by the tested slope reductions appear not to be restrictive in terms of peak values. Hence, they should not represent a relevant issue in terms of flow impact or cavitation damage for flow conditions similar to those analyzed in the present study, namely gradually varied or quasi-uniform self-aerated flow upstream of the slope reduction.

Author Contributions: Conceptualization, A.J.S. and J.M.; methodology, M.J.O.M.T., A.J.S., M.P. and J.M.; validation, M.J.O.M.T., A.J.S., M.P. and J.M.; formal analysis, M.J.O.M.T., J.M., A.J.S. and M.P.; investigation, M.J.O.M.T.; resources, A.J.S. and J.M; data curation, M.J.O.M.T. and J.M.; writingoriginal draft preparation, M.J.O.M.T., writing—review and editing, M.J.O.M.T., J.M., A.J.S. and M.P.; visualization, M.J.O.M.T. and M.P.; supervision, A.J.S. and J.M.; project administration, A.J.S. and J.M.; funding acquisition, A.J.S., J.M., M.P. and M.J.O.M.T. All authors have read and agreed to the published version of the manuscript.

Funding: This study was conducted under the framework of the IST-EPFL Joint Doctoral Initiative, granted by the Laboratory of Hydraulic Constructions (LCH) of EPFL, and the Fundação para a Ciência e a Tecnologia (FCT), Portugal (grant SFRH/BD/51527/2011). The research was funded in part by the Ministry of Science, Research and Technology of Islamic Republic of Iran.

Institutional Review Board Statement: Not applicable.

Informed Consent Statement: Not applicable.

Data Availability Statement: Some or all data, models, or code that support the findings of this study are available from the corresponding author upon reasonable request.

Acknowledgments: The authors thank Xueqin Zheng for her assistance during the tests.

Conflicts of Interest: The authors declare no conflict of interest.

\section{Notations}

The following symbols are used in this paper.

C local air concentration (-)

$C_{m} \quad$ mean air concentration (-)

$C_{\text {mup }} \quad$ mean air concentration upstream of, yet uninfluenced by, the slope reduction (-)

$d$ equivalent clear-water depth $(\mathrm{m})$

$d_{c} \quad$ critical flow depth (m)

$d_{0} \quad$ jet-box opening and related flow depth $(\mathrm{m})$

$d_{u p} \quad$ equivalent clear-water depth upstream of, yet uninfluenced by, the slope reduction (m)

$F \quad$ Probability distribution function of fluctuating pressures (-)

$\mathbf{F}_{o} \quad$ jet-box Froude number (-)

$g \quad$ gravitational acceleration $\left(\mathrm{m} / \mathrm{s}^{2}\right)$

$h \quad$ vertical step height $(\mathrm{m})$

$K_{u} \quad$ kurtosis (-)

$l \quad$ horizontal step length $(\mathrm{m})$

p bottom-pressure (Pa) 


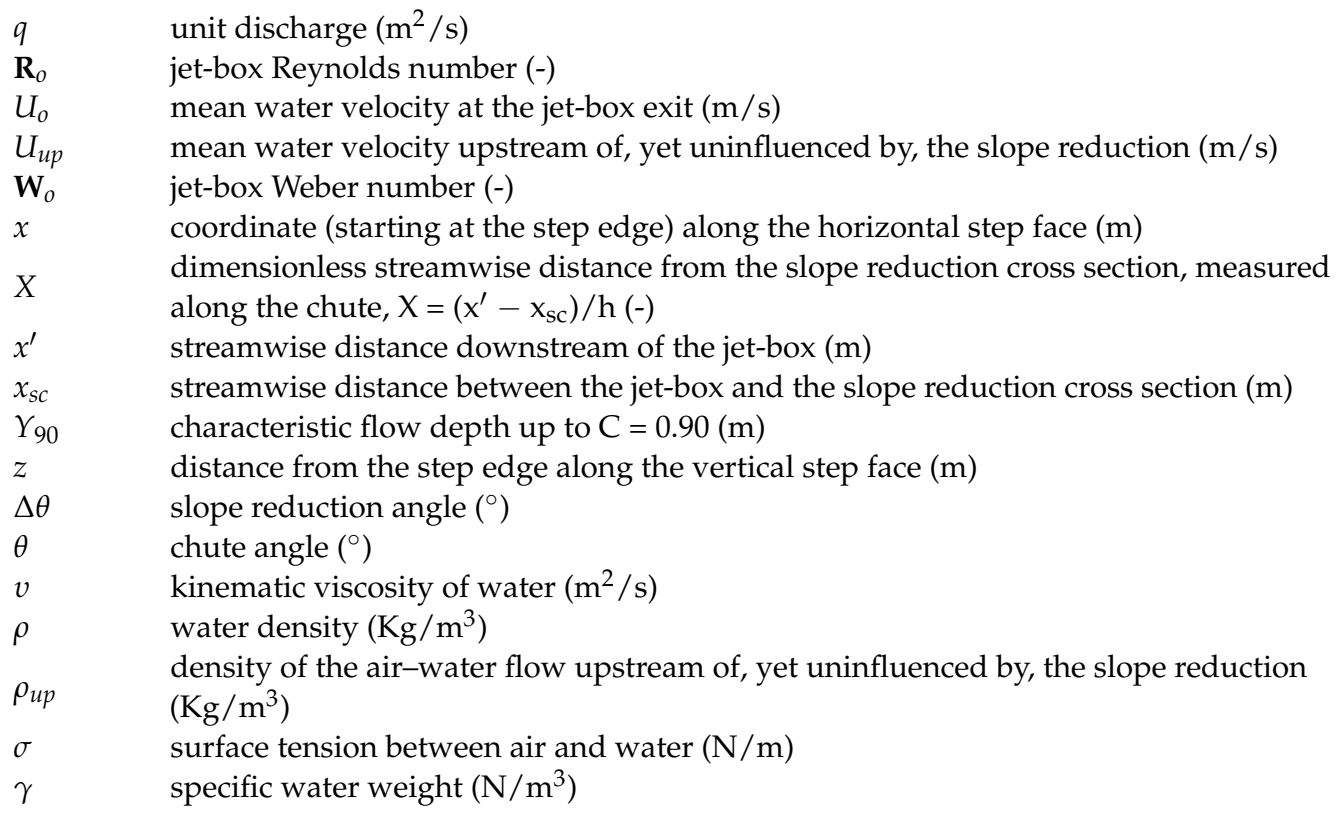

\section{References}

1. Matos, J.; Sánchez-Juny, M.; Quintela, A.; Dolz, J. Air Entrainment and Safety Against Cavitation Damage in Stepped Spillways over RCC Dams. In Proceedings of the International Workshop Hydraulics of Stepped Spillways, ETH Zurich, Switzerland, 22-24 March 2000; Minor, H.-E., Hager, W.H., Eds.; Balkema: Rotterdam, The Netherlands, 2000; pp. 69-76.

2. Sánchez-Juny, M.; Pomares, J.; Dolz, J. Pressure Field in Skimming Flow over a Stepped Spillway. In Proceedings of the Workshop Hydraulics of Stepped Spillways, ETH Zurich, Switzerland, 22-24 March 2000; Minor, H.-E., Hager, W.H., Eds.; Balkema: Rotterdam, The Netherlands, 2000; pp. 137-145.

3. Sánchez-Juny, M.; Bladé, E.; Dolz, J. Pressures on a Stepped Spillway. J. Hydraul. Res. 2007, 45, 505-511. [CrossRef]

4. Sánchez-Juny, M.; Bladé, E.; Dolz, J. Analysis of Pressures on a Stepped Spillway. J. Hydraul. Res. 2008, 46, 410-414. [CrossRef]

5. André, S. High Velocity Aerated Flows over Stepped Chutes with Macro-Roughness Elements. Ph.D. Thesis, École Polytechnique Fédérale de Lausanne, Lausanne, Switzerland, 2004.

6. Sánchez-Juny, M.; Dolz, J. Experimental Study of Transition and Skimming Flows on Stepped Spillways in RCC Dams: Qualitative Analysis and Pressure Measurements. J. Hydraul. Res. 2005, 43, 540-548. [CrossRef]

7. Gomes, J.F. Campo de Pressões: Condições de Incipiência à Cavitação em Vertedouros em Degraus com Declividade 1V:0.75H (Pressure Field: Conditions of Incipient Cavitation on Stepped Spillways with Slopes of 1V: 0.75H). Ph.D. Thesis, Federal University of Rio Grande do Sul, Porto Alegre, Brazil, 2006. (In Portuguese).

8. Gomes, J.F.; Amador, A.T.; Marques, M.; Matos, J.; Sánchez-Juny, M. Hydrodynamic Pressure Field on Steeply Sloping Stepped Spillways. In Proceedings of the International Junior Researcher and Engineer Workshop on Hydraulic Structures, Montemoro-Novo, Portugal, 2-4 September 2006; Matos, J., Chanson, H., Eds.; Hydraulic Model Report No. CH61/06. Div. of Civil Engineering, The University of Queensland: Brisbane, Australia, 2006; pp. 71-80.

9. André, S.; Schleiss, A.J. Discussion of "Pressures on a Stepped Spillway". J. Hydraul. Res. 2008, 46, 574-576. [CrossRef]

10. Khatsuria, R.M. Discussion of "Experimental Study of Transition and Skimming Flows on Stepped Spillways in RCC Dams: Qualitative Analysis and Pressure Measurements". J. Hydraul. Res. 2008, 46, 175-176. [CrossRef]

11. Amador, A.; Sánchez-Juny, M.; Dolz, J. Developing Flow Region and Pressure Fluctuations on Steeply Sloping Stepped Spillways. J. Hydraul. Eng. 2009, 135, 1092-1100. [CrossRef]

12. Takahashi, M.; Ohtsu, I. Aerated Flow Characteristics of Skimming Flow over Stepped Chutes. J. Hydraul. Res. 2012, 50, 427-434. [CrossRef]

13. Zhang, J.M.; Chen, J.G.; Wang, Y. Experimental Study on Time-Averaged Pressure in Stepped Spillway. J. Hydraul. Res. 2012, 50, 236-240. [CrossRef]

14. Zarrati, A.M.; Jin, Y.C.; Shanehsaz-Zadeh, A.; Ahadi, F. Potential flow Solution for a Free Surface Flow Past a Sudden Slope Change. Can. J. Civil Eng. 2004, 31, 553-560. [CrossRef]

15. Houston, K.L. Hydraulic Model Studies of Upper Spillway Dam Stepped Spillway and Outlet Works; Report REC-ERC-87-6; USBR: Denver, CO, USA, 1987.

16. Baumann, A.; Arefi, F.; Schleiss, A.J. Design of Two Stepped Spillways for a Pumped Storage Scheme in Iran. In Proceedings of the International Conference Hydro 2006-Maximizing the Benefits of Hydropower, Porto Carras, Greece, 25-27 September 2006.

17. Ostad Mirza, M.J.; Matos, J.; Pfister, M.; Schleiss, A.J. The Effect of an Abrupt Slope Change on Air Entrainment and Flow Depths at Stepped Spillways. J. Hydraul. Res. 2016, 55, 362-375. [CrossRef] 
18. Ostad Mirza, M.J. Experimental Study on the Influence of Abrupt Slope Changes on Flow Characteristics over Stepped Spillways. Ph.D. Thesis, École Polytechnique Fédérale de Lausanne, Lausanne, Switzerland, 2016. [CrossRef]

19. Schwalt, M.; Hager, W.H. Jet box. Schweiz. Ing. Architekt. 1992, 110, 547-549. (In German)

20. Chanson, H. Hydraulics of Skimming Flows on Stepped Chutes: The Effects of Inflow Conditions? J. Hydraul. Res. 2006, 44, 51-60. [CrossRef]

21. Boes, R.M.; Hager, W.H. Two-Phase Flow Characteristics of Stepped Spillways. J. Hydraul. Eng. 2003, 129, 661-670. [CrossRef]

22. Amador, A. Comportamiento Hidráulico de los Aliviaderos Escalonados en Presas de Hormigón Compactado (Hydraulic Behavior of Stepped Spillways on RCC Dams). Ph.D. Thesis, Universitat Politècnica de Catalunya, Barcelona, Spain, 2005. (In Spanish).

23. Pfister, M.; Chanson, H. Two-Phase Air-Water Flows: Scale Effects in Physical Modeling. J. Hydrodyn. 2014, 26, 291-298. [CrossRef]

24. Sánchez-Juny, M. Comportamiento Hidraulico de los Aliviaderos Escalonados en Presas de Hormigón Compactado. Analisis del Campo de Presiones. (Hydraulic Behaviour of Stepped Spillways in RCC Dams: Analysis of the Pressure Field). Ph.D. Thesis, Universitat Politècnica de Catalunya, Barcelona, Spain, 2001. (In Spanish).

25. Gonzalez, C.A.; Chanson, H. Interactions between Cavity Flow and Main Stream Skimming Flows: An Experimental Study. Can. J. Civil Eng. 2004, 31, 33-44. [CrossRef]

26. Henderson, F.M. Open Channel Flow; Macmillan Publishing Co., Inc.: New York, NY, USA, 1996.

27. USBR. Design of Small Dams, 3rd ed.; US Government Printing Office: Washington, DC, USA, 1987.

28. Tennekes, H.; Lumley, J.L. A First Course in Turbulence; The MIT Press: Cambridge, MA, USA; London, UK, 1972.

29. Pfister, M.; Hager, W.H.; Minor, H.-E. Stepped Chutes: Pre-aeration and Spray Reduction. Intl. J. Multiphase Flow. 2006, 32, 269-284. [CrossRef]

30. Schiess, A.; Pfister, M.; Hager, W.H.; Minor, H.-E. Hydraulic Performance of Step Aerator. J. Hydraul. Eng. 2008, 134, 127-134.

31. Frizell, K.W.; Renna, F.M.; Matos, J. Cavitation Potential of Flow on Stepped Spillways. J. Hydraul. Eng. 2013, 139, 630-636. [CrossRef]

32. Frizell, K.W.; Renna, F.M.; Matos, J. Closure to Cavitation Potential of Flow on Stepped Spillways. J. Hydraul. Eng. 2015, 141, 07015009. [CrossRef] 